\title{
Prevalência e aspectos anatomopatológicos das neoplasias primárias do coração, de tecidos da base do coração e metastáticas, em cães do Sul de Minas Gerais (1994-2009) ${ }^{1}$
}

\author{
Leonardo P. Mesquita², Camila C. Abreu², Clayton I. Nogueira², Angélica T.B. Wouters ${ }^{3}$, \\ Flademir Wouters ${ }^{2}$, Pedro S. Bezerra Júnior ${ }^{2}$, Ruthnéia A.L. Muzzi ${ }^{4}$ e Mary S. Varaschin ${ }^{2 *}$
}

\begin{abstract}
Mesquita L.P., Abreu C.C., Nogueira C.I., Wouters A.T.B., Wouters F., Bezerra Jr P.S., Muzzi R.A.L. \& Varaschin M.S. 2012. [Prevalence and anatomopathological findings of primary cardiac neoplasms of the heart base tissues and metastases in dogs from southern Minas Gerais, Brazil (1994-2009).] Prevalência e aspectos anatomopatológicos das neoplasias primárias do coração, de tecidos da base do coração e metastáticas, em cães do Sul de Minas Gerais (1994-2009). Pesquisa Veterinária Brasileira 32(11):11551163. Setor de Patologia Veterinária, Departamento de Medicina Veterinária, Universidade Federal de Lavras, Campus Universitário, Caixa Postal 3037, Inácio Valentim, Lavras, MG 37200-000, Brazil.E-mail: msvaraschin@dmv.ufla.br

The purpose of this study was to determine the prevalence and anatomopathological findings of primary and metastatic heart tumors and from heart base tumors diagnosed in dogs from southern Minas Gerais, Brazil. The diagnosis was based on histological characteristics and immunophenotyping of the tumors cells. From 1994 to 2009, 2397 necropsies of dogs were performed. Cardiac neoplasms were diagnosed in 31 dogs $(1.29 \%)$, where seven $(22.58 \%)$ were primary and $24(77.42 \%)$ were metastatic. Neoplasms of the heart diagnosed as primary were hemangiosarcoma (1/7) and myxoma (1/7), and, primary of heart base, the chemodectoma (3/7) and ectopic thyroid carcinoma (2/7). Frequency was higher in male dogs (5/7), of Boxer breed (3/7) with mean age of $9.7 \pm 1.88$ years. In metastatic neoplasms, the frequency was higher in female dogs (15/24), of Rottweiler breed $(7 / 24)$ with the mean age of $7.5 \pm 3.23$ years. The $T$ cell lymphoma $(7 / 27)$ was the most frequent neoplasm, diagnosed as metastatic.
\end{abstract}

INDEX TERMS: Cardiac neoplasms, dogs, heart base, pathology.

\begin{abstract}
RESUMO.- Este estudo teve como objetivo determinar a prevalência e achados anatomopatológicos de tumores primários e metastáticos do coração ou de tecidos da base do coração, diagnosticados em caninos do Sul de Minas Gerais. 0 diagnóstico foi realizado mediante análise histopatológica e imuno-histoquímica das neoplasias. Durante os anos de 1994-2009, foram realizadas 2397 necropsias em caninos. Neoplasias no coração foram detectadas em

\footnotetext{
${ }^{1}$ Recebido em 23 de abril de 2012.

Aceito para publicação em 31 de agosto de 2012.

${ }^{2}$ Setor de Patologia Veterinária, Departamento de Medicina Veterinária, Universidade Federal de Lavras (UFLA), Cx. Postal 3037, Lavras, MG 37200000, Brasil.*Autor para correspondência: msvaraschin@dmv.ufla.br

${ }^{3}$ Setor de Patologia Veterinária, Faculdade de Medicina Veterinária, Universidade José do Rosário Vellano (Unifenas), Campus Universitário, Rodovia MG 179 Km 0, Alfenas, MG 37130-000, Brasil.

${ }^{4}$ Setor de Clínica e Cirurgia Veterinária, Departamento de Medicina Veterinária, UFLA, Lavras, MG.
}

31 cães $(1,29 \%)$, onde, sete $(22,58 \%)$ eram primárias e 24 $(77,42 \%)$ metastáticas. As neoplasias diagnosticadas como primárias do coração foram o hemangiossarcoma (1/7) e o mixoma (1/7); e como primárias da base do coração o quimiodectoma (3/7) e o carcinoma de tireoide ectópica (2/7). A frequência foi maior em cães machos (5/7), da raça Boxer (3/7) e com idade média de $9,7 \pm 1,88$ anos. Nas neoplasias metastáticas, a frequência foi maior em fêmeas (15/24), em cães da raça Rottweiler (7/24) e a idade média foi de 7,5 $\pm 3,23$ anos, sendo o linfoma de células $\mathrm{T}$ a neoplasia metastática de maior ocorrência $(7 / 27)$.

TERMOS DE INDEXAÇÃO: Neoplasias cardíacas, cães, base do coração, patologia.

\section{INTRODUÇÃO}

Tumores primários do coração são raros em caninos, sendo o hemangiossarcoma o mais frequentemente relatado 
(Walter \& Rudolph 1996, Girard et al. 1999, Ware \& Hopper 1999). Os tumores da base do coração, considerados neoplasias primárias dos tecidos extracardíacos, como o quimiodectoma (Kim et al. 2005, Aupperle et al. 2007, Headley et al. 2009, Nakagawa et al. 2009) e o carcinoma de tireoide ectópica (Constantino-Casas et al. 1996, Walter \& Rudolph 1996, Ware \& Hopper 1999), ocorrem frequentemente em cães e podem afetar a função cardíaca, por comprimirem os vasos da base do coração e por infiltrarem no tecido cardíaco, como foi descrito por Almes et al. (2008) em um carcinossarcoma de tireoide ectópica e por Cavalcanti et al. (2006) em um quimiodectoma maligno. 0 quimiodectoma é o tumor de maior ocorrência, depois do hemangiossarcoma cardíaco (Walter \& Rudolph 1996, Ware \& Hopper 1999). Também são descritos como tumores primários do coração em caninos o rabdomiossarcoma (Aupperle et al. 2007), o rabdomioma (Girard et al. 1999, Radi \& Metz 2009), o fibrossarcoma (Madarame et al. 2004, Speltz et al. 2007), o neurofibrossarcoma (Aupperle et al. 2007), os mesenquimomas malignos (tumores constituídos por vários tipos de células mesenquimais) (Machida et al. 2002), o schwannoma maligno (Wohlsein et al. 2005), o condrossarcoma (Albers et al. 1997, LaRock et al. 1997), o osteossarcoma (Schelling \& Moses 1994, Warman et al. 2006), o mixoma (Symbas et al. 1976), o mixoma valvular (Machida et al. 2003, Akkoc et al. 2007), o leiomiossarcoma (Fews et al. 2008), o mesotelioma (Cobb \& Brownlie 1992, Girard et al. 1999, Brower et al. 2006), o lipoma (Brambilla et al. 2006, Ben-Amotz et al. 2007) e o sarcoma miofibroblástico (Grieco et al. 2008).

Tumores metastáticos para o coração são, de maneira geral, mais frequentes que os primários (Walter \& Rudolph 1996, Kisseberth 2001). Num estudo retrospectivo de 83 cães com doença neoplásica em estágio terminal, em 11 foram diagnosticados tumores primários do coração e, em 24, metastáticos (Aupperle et al. 2007). Vários tipos de neoplasia podem atingir o coração, entre eles carcinomas, linfomas, hemangiossarcoma (Aupperle et al. 2007), fibrossarcoma, rabdomiossarcoma, melanoma, mastocitoma, feocromocitoma e histiocitose maligna disseminada (Girard et al. 1999).

Os sinais clínicos observados em cães com neoplasia cardíaca são muito variáveis, o que pode dificultar o diagnóstico (Kisseberth 2001), porém alguns sinais, como sopro e arritmias, podem sugerir doença cardíaca. Geralmente o quadro clínico está relacionado com a localização anatômica do tumor (Kisseberth 2001, Aupperle et al. 2007) e não necessariamente com sua classificação histológica (Kisseberth 2001).

Este trabalho relata a prevalência e os achados anatomopatológicos dos diversos tumores que afetaram o coração de caninos, provenientes do sul de Minas Gerais, no período de 1994 a 2009, bem como descreve os sinais clínicos apresentados.

\section{MATERIAL E MÉTODOS}

Este estudo foi baseado em um total de 2397 necropsias de caninos realizadas no período de 1994-2008 na Universidade José do Rosário Vellano e no período de 1999-2009 na Universidade Federal de Lavras (UFLA). Neoplasias primárias do coração, da base do coração e metastáticas foram detectadas em 31 cães. Os dados referentes aos caninos necropsiados incluem idade, raça, gênero, histórico clínico e resultados dos exames físicos.

Em todas as necropsias, o coração foi dissecado e inspecionado macroscopicamente. Fragmentos do coração e dos demais tecidos foram coletados, fixados em formalina a 10\% tamponada e processados rotineiramente para histologia. Cortes de $5 \mu \mathrm{m}$ de espessura foram corados pela Hematoxilina e Eosina (HE) e avaliados por microscopia ótica. Amostras em que foi visualizada matriz mixoide foi realizada a coloração de azul de Alciano pH 2,5.

Cortes histológicos das neoplasias de células redondas, daquelas localizadas na base do coração e daquelas oriundas de endotélio vascular foram submetidos a imuno-histoquímica (IHQ) pelo método estreptavidina-biotina-peroxidase. Para as neoplasias de células redondas, como anticorpos primários utilizaram-se anti-CD3 (para marcação de linfócitos T - Dako, cód. A0452), anti-CD18 (leucócitos/+macrófagos - Clone CA16.3C10, UC Davis), anti-Lambda light chain (linfócitos B - clone HP6054, Zymed), anti-BLA36 (linfócitos B, anti-human linfócitos B antigeno 36, Dako M533) e anti-CD117 (mastócito, Clone c-KIT, Dako, A4502), nas diluições de 1:50, 1:20, 1:50, 1:40 e 1:800, respectivamente. Para diferenciação entre as neoplasias da base do coração foram utilizados como anticorpos primários a anti-cromogranina A (Dako, cód. A0430) e anti-enolase neurônio específica (NSE) (Dako, cód. M0873) nas diluições de 1:200, anti-sinaptofisina (Dako, clone SY38, cód. M0776) na diluição de 1:50, e anti-tireoglobulina (Dako, cód. A0251) na diluição de 1:300. Para confirmação do diagnóstico das neoplasias oriundas de endotélio vascular foi utilizado o anticorpo anti-fator VIII (Dako, cód.A0082) na diluição de 1:200. Na recuperação antigênica utilizou-se o calor em micro-ondas (1000W) por 6 minutos em tampão citrato pH 6,0 (CD3, CD18, Lambda light chain e BLA.36), banho-maria por 20 minutos em panela comercial com capacidade para 1,5L previamente aquecida a $100^{\circ} \mathrm{C}(\mathrm{CD} 117$, cromogranina $\mathrm{A}$, sinaptofisina, e fator VIII), e em panela de pressão (DakoCytomation) a $96^{\circ} \mathrm{C}$ por 40 minutos (enolase neurônio específica) e 20 minutos (tireoglobulina). A incubação em estufa a $37^{\circ} \mathrm{C}$ com tripsina a $0,1 \%$ em câmara úmida por 10 minutos também foi realizada após o tratamento com o calor (Lambda light chain). As lâminas foram incubadas com o anticorpo primário em câmara úmida overnigth a $4^{\circ} \mathrm{C}$ e posteriormente, utilizou-se anticorpo secundário biotinalado conjugado a streptavidina (kit LSAB, Dako). Para o BLA.36 utilizou-se um kit comercial (Kit Dako Ark, cód. K3955), onde conforme recomendações do fabricante, a reação entre o anticorpo primário, secundário e um bloqueador de reações inespecíficas ocorrem separadamente em um recipiente. Após, o preparado do anticorpo é incubado no corte histológico por $30 \mathrm{~min}$. Na revelação utilizou-se o DAB (3,3'-diaminobenzidina, Dako) ou Vector Novared ${ }^{\circledR}$, como cromógeno. Como controles positivos, foram utilizados tecidos de cães: linfonodo (CD3, Lambda light chain, BLA36), pele com inflamação piogranulomatosa (CD18), pele normal (CD117), adrenal (cromogranina A), hipófise (sinaptofisina), córtex cerebral (enolase neurônio específica) e tireoide (tireoglobulina).

\section{RESULTADOS}

Neoplasias primárias ou metastáticas do coração e primárias da base do coração foram detectadas em 31 cães (14 machos e 17 fêmeas). A prevalência geral foi de 1,29\%. A idade variou de dois a 15 anos, com média de $8 \pm 3,09$ anos.

\section{Tumores primários do coração e da base do coração}

As neoplasias primárias do músculo cardíaco e da base do coração foram detectadas em sete cães $(22,58 \%)$ do to- 
Quadro 1. Neoplasias primárias do coração e da base do coração em caninos, diagnosticadas na UFLA Lavras/MG e na Unifenas, Alfenas/MG, no período de 1994-2009

\begin{tabular}{clccccc}
\hline Canino & \multicolumn{1}{c}{ Raça } & $\begin{array}{c}\text { Idade } \\
\text { (anos) }\end{array}$ & Sexo & Neoplasia & $\begin{array}{c}\text { Tamanho (diâ- } \\
\text { metro em cm) }\end{array}$ & Metástases \\
\hline 1 & Rottweiler & 10 & F & Mixoma AD & 6 & Ausentes \\
2 & Pastor Alemão & 8 & M & Hemangiossarcoma AD & 1,5 & Pulmões, fígado e rins \\
3 & Boxer & 7 & M & Quimiodectoma & 1,5 & Ausentes \\
4 & Boxer & 10 & M & Quimiodectoma maligno & 5 & Ausentes \\
5 & Boxer & 9 & F & Quimiodectoma & 2,5 & Ausentes \\
6 & SRD & 12 & M & Carcinoma de tireoide ectópica & 5 & Baço, fígado e rins \\
7 & Dogue Alemão & 12 & M & Carcinoma de tireoide ectópica & 0,4 & Ausentes
\end{tabular}

$\overline{\mathrm{SRD}}=$ sem raça definida, $\mathrm{M}=$ macho, $\mathrm{F}$ = fêmea, $\mathrm{AD}=$ átrio direito.

Quadro 2. Sinais clínicos apresentados pelos caninos com neoplasia primária do miocárdio e da base do coração diagnosticadas na UFLA, Lavras/MG e na Unifenas, Alfenas/ MG, no período de 1994-2009

\begin{tabular}{lcc}
\hline \multicolumn{1}{c}{ Sinal clínico } & Frequência & $\%$ \\
\hline Apatia & $4 / 5$ & 80 \\
Tosse & $4 / 5$ & 80 \\
Sopro cardíaco & $4 / 5$ & 80 \\
Anorexia & $2 / 5$ & 40 \\
Mucosas pálidas & $2 / 5$ & 40 \\
Crepitações pulmonares & $2 / 5$ & 40 \\
Déficit de pulso & $1 / 5$ & 20 \\
Arritmias cardíacas & $1 / 5$ & 20 \\
Caquexia & $1 / 5$ & 20 \\
Dispneia & $1 / 5$ & 20 \\
Desidratação & $1 / 5$ & 20 \\
Midríase & $1 / 5$ & 20 \\
Síncope & $1 / 5$ & 20 \\
Hiporexia & $1 / 5$ & 20 \\
Oligúria & $1 / 5$ & 20
\end{tabular}

tal de 31 cães (Quadro 1). A idade média desses caninos foi de 9,71 $\pm 1,88$ anos, sendo que seis eram de médio a grande porte e um canino de pequeno porte. A raça mais frequentemente afetada foi o Boxer (3/7), sendo que do total de cães com neoplasia cardíaca primária, 71,4\% (5/7) eram machos e $28,6 \%$ (2/7) fêmeas.

Os principais achados no exame clínico dos caninos estão demonstrados no Quadro 2. 0 canino 1 estava obeso e apresentou alguns sinais inespecíficos, tais como apatia, hiporexia e êmese. Ao exame eletrocardiográfico, havia uma onda $\mathrm{R}$ de baixa amplitute, que não é patognomônica de doença cardíaca. Neste animal, foi diagnosticado hipotireoidismo. 0 canino 2 veio a óbito após três semanas de apatia, mucosas pálidas e andar cambaleante. 0 canino 3 apresentou sopro cardíaco, tosse e foi eutanasiado por apresentar inúmeras crises convulsivas. 0 canino 4 apresentou tosse seca não contínua por um período de aproximadamente um mês, com evolução do quadro para síncopes, seguidas de cianose. Ao exame físico, foram observados déficit de pulso, crepitações pulmonares, arritmias cardíacas, sopro holossistólico em focos mitral, aórtico e pulmonar. 0 animal veio a óbito num período de aproximadamente uma semana após o início das síncopes. Os sinais clínicos do canino 5 não foram relatados. 0 canino 6 apresentou histórico de hiporexia, apatia e oligúria. Ao exame físico, foram detectados sopro holossistólico grau 6/6 em mitral e tricúspide, além de crepitações pulmonares. Ao exame ecoDopplercardiográfico, havia derrame pericárdico acentuado e uma massa de aproximadamente $5,0 \mathrm{~cm}$ de diâmetro na base do coração, aderida à aorta, de ecogenicidade mista. $\mathrm{Na}$ pericardiocentese, foram retirados $150 \mathrm{~mL}$ de líquido pericárdico e enviado para análise citopatológica. 0 animal veio ao óbito um mês após o diagnóstico citopatológico de carcinoma de tireoide ectópica. Não foi possível coletar informações sobre histórico e achados clínicos do canino 7.

Achados anatomopatológicos. 0 mixoma (Quadro 1) localizado no átrio direito do canino 1 apresentava $6,0 \mathrm{~cm}$ de diâmetro e se projetava parcialmente na luz desta câmara, mantendo, no entanto, a integridade do endocárdio. Ao corte, possuía coloração esbranquiçada (Fig.1). Histologicamente, a neoplasia era bem delimitada, constituída por células fusiformes, paralelamente distribuídas e frouxamente arranjadas em matriz mixoide (Fig.2). Apresentavam núcleos basofílicos fusiformes, algumas vezes vacuolizados, nucléolos evidentes e citoplasma eosinofilico com bordos pouco definidos. A matriz mixoide foi evidenciada pela coloração azul de Alciano pH 2,5. Havia ainda cerca de $2 \mathrm{~L}$ de líquido ligeiramente avermelhado na cavidade abdominal e $750 \mathrm{~mL}$ de líquido translúcido na cavidade torácica. 0 fígado estava moderadamente congesto.

No canino 2, foi diagnosticado hemangiossarcoma na parede do átrio direito, com $1,5 \mathrm{~cm}$ de diâmetro, aspecto nodular, superfície irregular e avermelhada e consistência macia. Havia nódulos de 0,3-0,6 cm de diâmetro, avermelhados, distribuídos por todas as superfícies pulmonar, hepática e renal, porém nas duas últimas, em quantidade re-

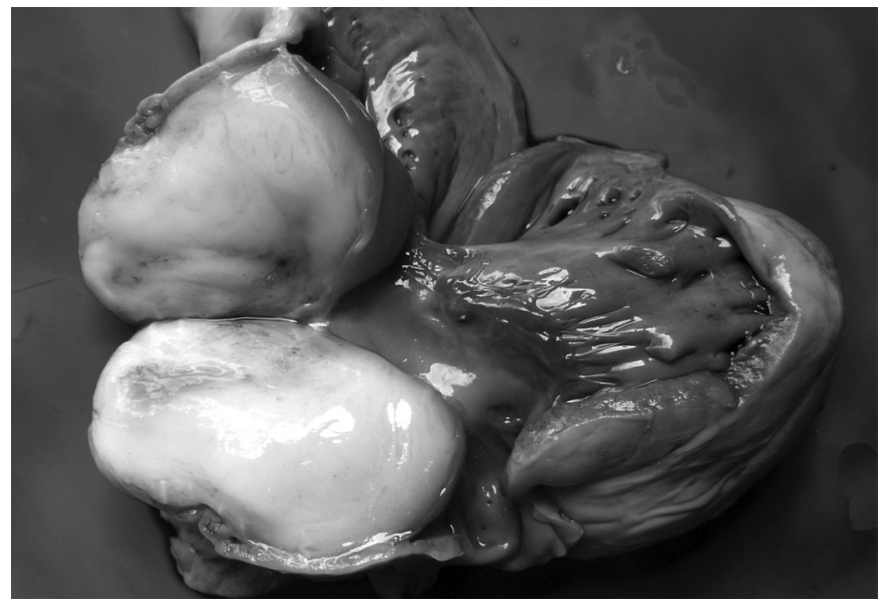

Fig.1. Mixoma presente no átrio direito do canino 1, fêmea, Rottweiler, com 10 anos de idade. A neoplasia possui $6,0 \mathrm{~cm}$ de diâmetro e coloração esbranquiçada ao corte. 


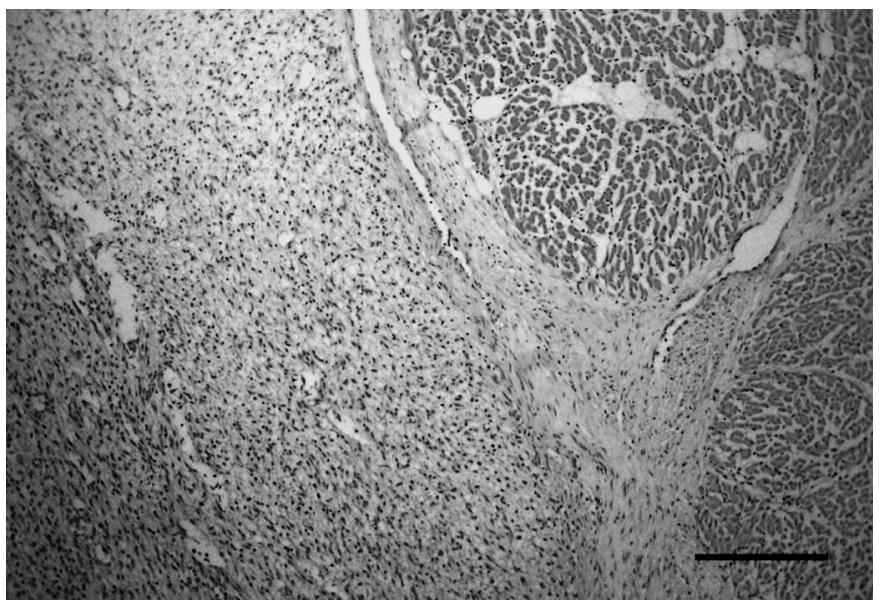

Fig.2. Aspecto microscópico do mixoma do canino 1, fêmea, Rottweiler, com 10 anos de idade. A neoplasia é constituída por células fusiformes arranjadas em matriz mixoide, nota-se na porção superior e inferior direita da figura, o músculo estriado cardíaco do átrio direito. HE, barra $200 \mu \mathrm{m}$.

duzida. 0 saco pericárdico continha quantidade moderada de sangue. Histologicamente, a neoplasia possuía células pleomórficas, fusiformes a ovaladas, com núcleos fusiformes basofílicos a hipercromáticos e citoplasma escasso, eosinofílico e de bordos pouco definidos. Essas células se organizavam formando estruturas semelhantes a vasos sanguíneos, e as mesmas foram positivas na imuno-histoquímica para o fator VIII.

Três neoplasias foram diagnosticadas como quimiodectoma. 0 tamanho das massas neoplásicas variou de 1,5$5,0 \mathrm{~cm}$ de diâmetro (Quadro 1) e estas eram firmes, róseas a esbranquiçadas. No canino 3, a neoplasia localizava-se na base da aorta e comprimia os vasos adjacentes. Havia hipertrofia concêntrica moderada do ventrículo esquerdo e hipertrofia excêntrica do ventrículo direito, assim como endocardiose moderada em valva mitral. Os pulmões estavam congestos. No canino 4, a neoplasia circundava parcialmente o tronco pulmonar e completamente o arco aórtico. Esta infiltrava o átrio esquerdo e projetava-se $0,5 \mathrm{~cm}$ para a luz dessa câmara. 0 ventrículo esquerdo apresentava hipertrofia esquerda concêntrica moderada. No canino 5, a massa estava localizada na parede da aorta e havia hipertrofia concêntrica moderada do ventrículo esquerdo e dilatação do ventrículo direito. As valvas tricúspide e mitral apresentavam endocardiose moderada e endocardite valvular moderada na mitral e semilunar aórtica. Histologicamente, os quimiodectomas eram constituídos por células cuboides a poliédricas, agrupadas em ninhos separados por moderado estroma fibrovascular, com núcleos basofílicos arredondados a ovalados. 0 citoplasma era escasso, levemente eosinofílico e com bordos distintos. Havia acentuada anisocitose e anisocariose (com exceção do canino 5). No canino 4 , foram observadas várias células gigantes pleomórficas, algumas multinucleadas, e invasão do miocárdio e de vasos sanguíneos pelas células neoplásicas. Essas três neoplasias foram positivas na imuno-histoquímica para cromogranina A (Fig.3). As neoplasias dos caninos 3 e 5 também foram positivas para sinaptofisina e para a NSE (Fig.4). Todas es- sas três neoplasias foram negativas para tireoglobulina. $\mathrm{Na}$ neoplasia do canino 4 não foi possível a realização da IHQ para NSE e sinaptofisina, uma vez que não foi possível a obtenção de cortes histológicos para a realização das mesmas.

Carcinoma de tireoide ectópica foi diagnosticado nos caninos 6 e 7. No canino 6, caracterizava-se por uma massa com $5,0 \mathrm{~cm}$ de diâmetro, consistência firme e de coloração tendendo ao branco na superfície e ao corte. Havia várias áreas de hemorragia e necrose e a massa tumoral envolvia a artéria aorta, estava aderida ao saco pericárdico e infiltrava o átrio direito (Fig.5). Havia pericardite fibrinosa (Fig.5) e o saco pericárdico era preenchido por $150 \mathrm{~mL}$ de líquido amarelado contendo filetes de fibrina. Metástases de 1,0$3,0 \mathrm{~cm}$ de diâmetro foram observadas em baço, fígado e rins. 0 carcinoma de tireoide ectópica foi diagnosticado por meio do exame citopatológico ante mortem, em amostra de líquido pericárdico. A amostra era composta por células arredondadas, as quais se organizavam em grupos formando

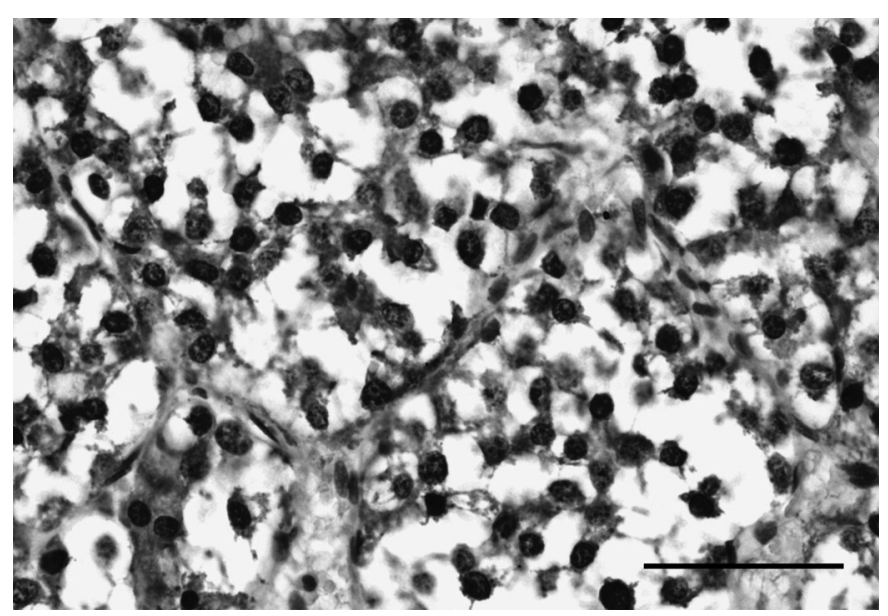

Fig.3. Quimiodectoma em canino 3, macho, Boxer, com 7 anos de idade. Nas células neoplásicas, evidencia-se forte marcação imuno-histoquímica intracitoplasmática para cromogranina A. IHQ pelo método estreptavidina-biotina-peroxidase, barra $50 \mu \mathrm{m}$.

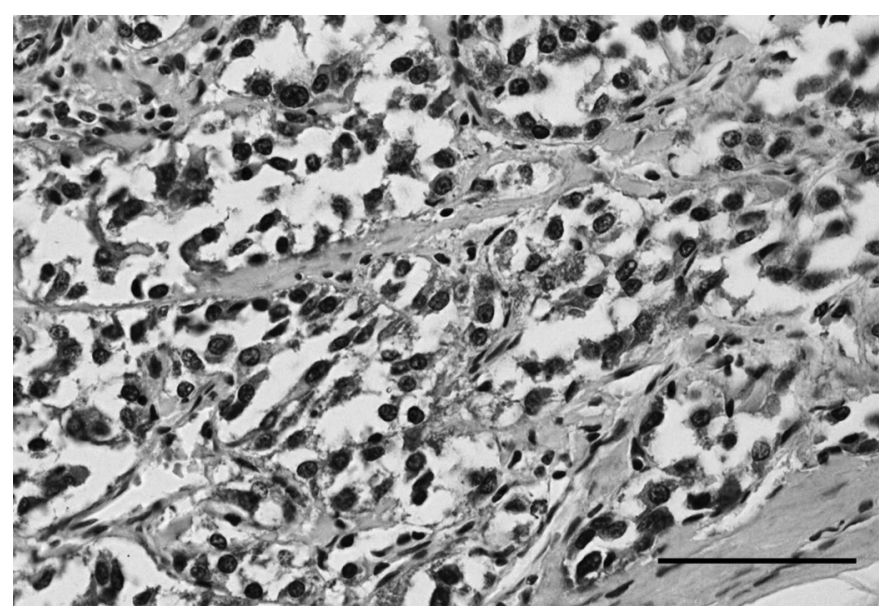

Fig.4. Quimiodectoma em canino 5, fêmea, Boxer, de 9 anos de idade. Há intensa marcação imuno-histoquímica nas células neoplásicas para enolase neurônio específica. IHQ pelo método estreptavidina-biotina-peroxidase, barra $50 \mu \mathrm{m}$. 


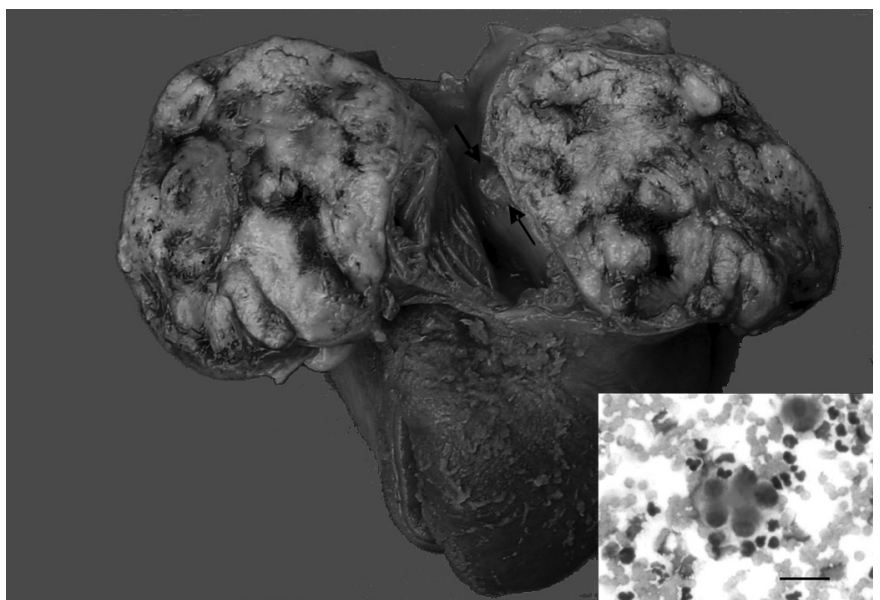

Fig.5. Carcinoma de tireoide ectópica no canino 6, macho, sem raça definida, com 12 anos de idade. A neoplasia se localizava na base do coração e ao corte, apresentava coloração esbranquiçada com áreas de hemorragia associadas a infiltração para o átrio direito (setas). Nota-se também pericardite fibrinosa. No detalhe observa-se, no exame citopatológico ante-mortem, de líquido pericárdico, células arredondadas dispostas a formar folículos. Romanowsky, barra $35 \mu \mathrm{m}$.

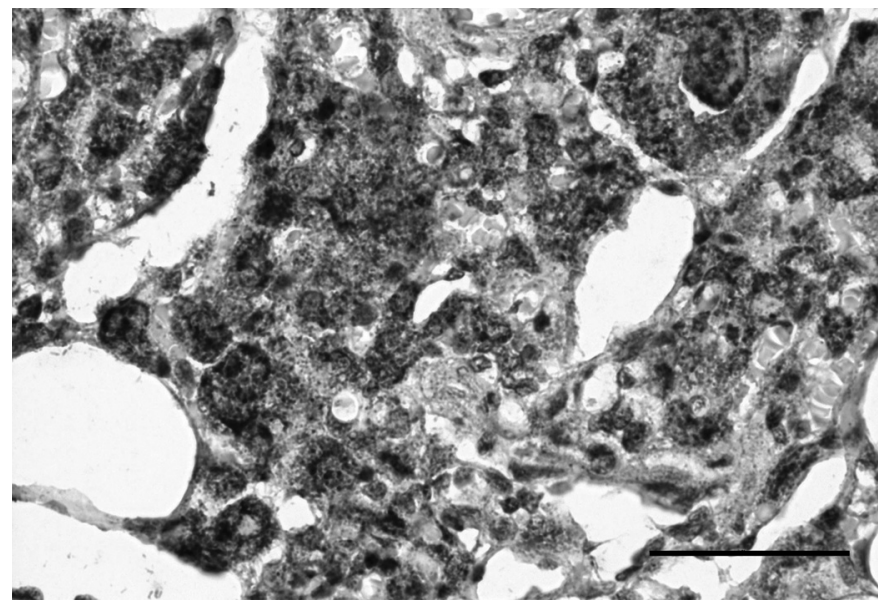

Fig.6. Carcinoma de tireoide ectópica no canino 7, macho, Dogue Alemão, com 12 anos de idade. Há intensa marcação intracitoplasmática na imuno-histoquímica para tireoglobulina. Nota-se também a formação de folículos. IHQ pelo método estreptavidina-biotina-peroxidase, barra $50 \mu \mathrm{m}$.

folículos que continham material eosinofílico (coloide) no interior (Fig.5). No canino 7, havia massa de $0,7 \mathrm{~cm}$ de diâmetro, lobulada, localizada entre o átrio e ventrículo direito. Havia dilatação do ventrículo direito, fígado congesto, com superfície irregular e consistência mais firme.

As alterações histológicas das neoplasias dos caninos 6 e 7 foram semelhantes. Eram compostas por células arredondadas, organizadas em grupos celulares por delgado estroma fibrovascular. 0 padrão compacto da neoplasia predominava no canino 6, embora houvesse áreas em que as células formavam folículos, por vezes contendo coloide. Os núcleos eram arredondados, basofílicos, com cromatina irregular, e apresentavam moderada anisocariose. 0 citoplasma era escasso, levemente eosinofílico e, por vezes, possuía bordos indistintos. As massas observadas em fígado, rins e baço do canino 6 foram histologicamente semelhantes ao observado na neoplasia primária. As células destas duas neoplasias apresentaram marcação na imuno-histoquímica para tireoglobulina (Fig.6), sendo negativas para cromogranina A.

\section{Tumores metastáticos no coração}

Nos 31 cães com neoplasias cardíacas, 24 delas $(77,42 \%)$ eram metastáticas. A idade média foi de 7,5 $\pm 3,23$ anos. A raça com maior ocorrência de metástases foi a Rottweiler (Quadro 3), sendo a idade média de 5,71 $\pm 2,28$ anos, e constituindo-se de 5 fêmeas e 2 machos. 0 diagnóstico das neoplasias metastáticas baseou-se nas características microscópicas e imuno-histoquímicas das mesmas e encontram-se relacionadas no Quadro 4.

A sintomatologia clínica dos caninos com neoplasias metastáticas para o coração foi bastante inespecífica e pobremente descrita, uma vez que muitos desses caninos não passaram por cuidados veterinários. Esta foi descrita como apatia, anorexia, emagrecimento progressivo, distensão abdominal, êmese e tosse. Somente dois caninos foram avaliados clinicamente. Um canino com metástase cardíaca de linfoma apresentou bradicardia e arritmias, sendo que outro, com o mesmo tipo de neoplasia, apresentou sopro cardíaco.

Quadro 3. Número e raça dos caninos com tumores metastáticos no coração diagnosticados na UFLA, Lavras/ MG e na UNIFENAS, Alfenas/MG no período de 1994-2009

\begin{tabular}{lcc}
\hline \multicolumn{1}{c}{ Raça } & Número de caninos & Frequência (\%) \\
\hline Rottweiler & 7 & 29,17 \\
SRD & 6 & 25,00 \\
Boxer & 3 & 12,50 \\
Dobermann Pinscher & 2 & 8,33 \\
Pastor Alemão & 2 & 8,33 \\
Labrador & 2 & 8,33 \\
Dogue Alemão & 1 & 4,17 \\
Fila Brasileiro & 1 & 4,17 \\
TOTAL & 24 & 100
\end{tabular}

$\overline{\mathrm{SRD}}=$ sem raça definida.

Quadro 4. Neoplasias metastáticas no coração diagnosticadas em caninos na UFLA, Lavras/MG e UNIFENAS, Alfenas/MG no período de 1994-2009

\begin{tabular}{lcc}
\hline \multicolumn{1}{c}{ Neoplasia primária } & Número de caninos & Frequência (\%) \\
\hline Linfoma & 7 & 29,17 \\
Hemangiossarcoma & 2 & 8,33 \\
Melanoma maligno & 2 & 8,33 \\
Carcinoma de glândula sudorípara & 1 & 4,17 \\
Carcinoma de próstata & 1 & 4,17 \\
Carcinoma hepatocelular & 1 & 4,17 \\
Carcinoma pancreático & 1 & 4,17 \\
Carcinoma sólido de mama & 1 & 4,17 \\
Carcinoma tubular renal & 1 & 4,17 \\
Carcinossarcoma de mama & 1 & 4,17 \\
Cistoadenocarcinoma renal & 1 & 4,17 \\
Fibrossarcoma & 1 & 4,17 \\
Histiocitose maligna sistêmica & 1 & 4,17 \\
Osteossarcoma & 1 & 4,17 \\
Rabdomiossarcoma & 1 & 4,17 \\
Seminoma maligno & 1 & 4,17 \\
TOTAL & 24 & 100
\end{tabular}


Achados anatomopatológicos. Todas as metástases cardíacas foram detectadas macroscopicamente. As metástases se caracterizaram sob a forma de nódulos de 0,2 a 3,0 cm de diâmetro, sendo que, em 14 dos 24 caninos, havia nódulos múltiplos no coração, abrangendo tanto átrio como ventrículo e, em seis caninos, estes estavam no átrio direito. Já, em quatro cães, as metástases foram visualizadas como extensas áreas esbranquiçadas infiltradas na musculatura cardíaca, como no linfoma demonstrado na Figura 7. Somente em um animal, com diagnóstico de fibrossarcoma da cavidade nasal, não houve metástase do tumor primário para outros órgãos além do coração.

Além das metástases cardíacas, foram encontrados hemopericárdio $(\mathrm{n}=1)$; dilatação ventricular bilateral $(\mathrm{n}=1)$; hipertrofia concêntrica do ventrículo esquerdo $(n=2)$; e hipertrofia concêntrica do ventrículo esquerdo associada a hipertrofia excêntrica de ambos os átrios $(\mathrm{n}=1)$. Somado a isso, em um Rottweiler de 5 anos com linfoma metastático multifocal, foram observadas dilatação ventricular bilateral

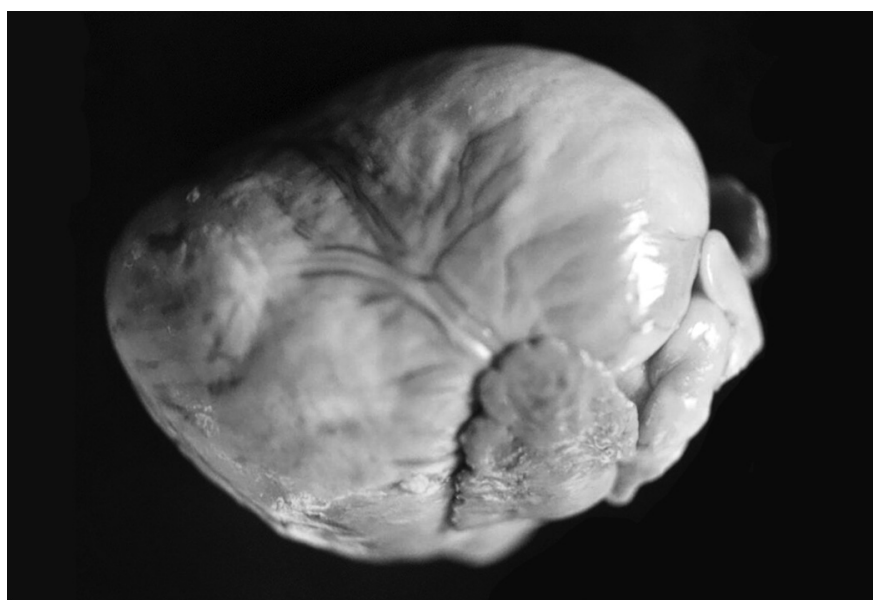

Fig.7. Linfoma localizado no coração de um canino, fêmea, sem raça definida, com 8 anos de idade. Notam-se extensas áreas esbranquiçadas infiltrando o músculo cardíaco, fazendo saliência na superfície do mesmo.

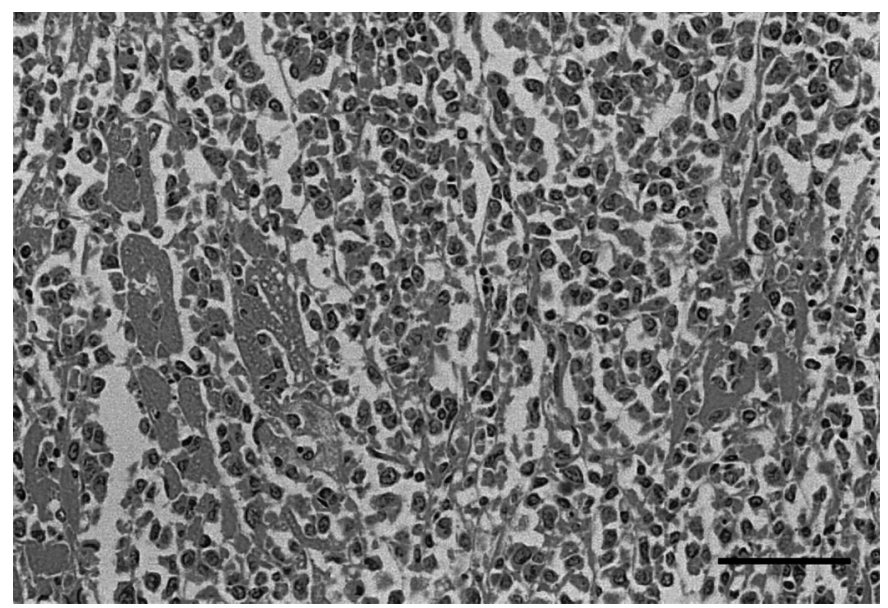

Fig.8. Mesmo canino da Figura 7. Neoplasia constituída por células arredondadas entremeadas na musculatura estriada cardíaca, com núcleos basofílicos e arredondados, com cromatina marginalizada e nucléolos evidentes. 0 citoplasma é escasso e eosinofílico. HE, barra $50 \mu \mathrm{m}$

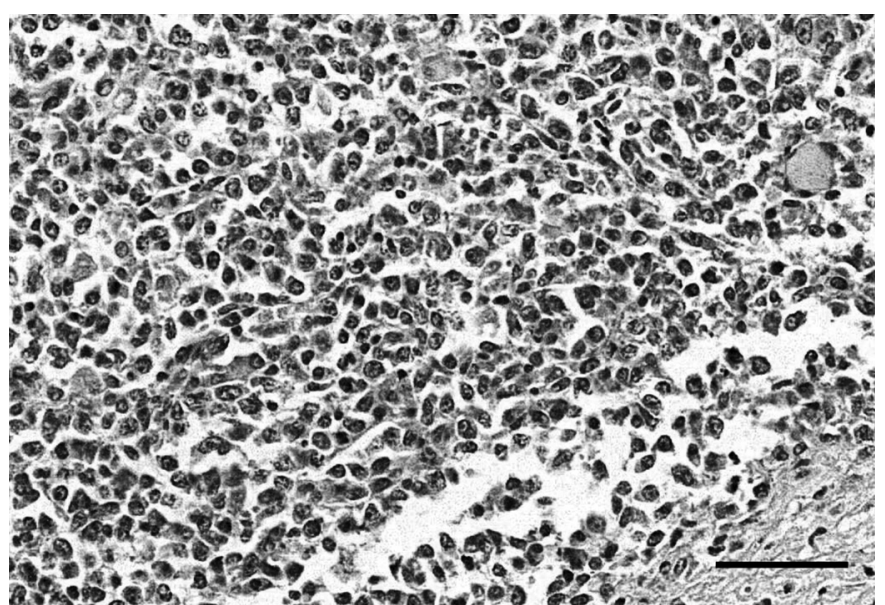

Fig.9. Linfoma localizado no coração de um canino, fêmea, Dogue Alemão, com 2 anos de idade. Nota-se intensa marcação intracitoplasmática para linfócitos T (anticorpo anti-CD3) nas células neoplásicas. IHQ pelo método estreptavidina-biotina-peroxidase, barra $50 \mu \mathrm{m}$.

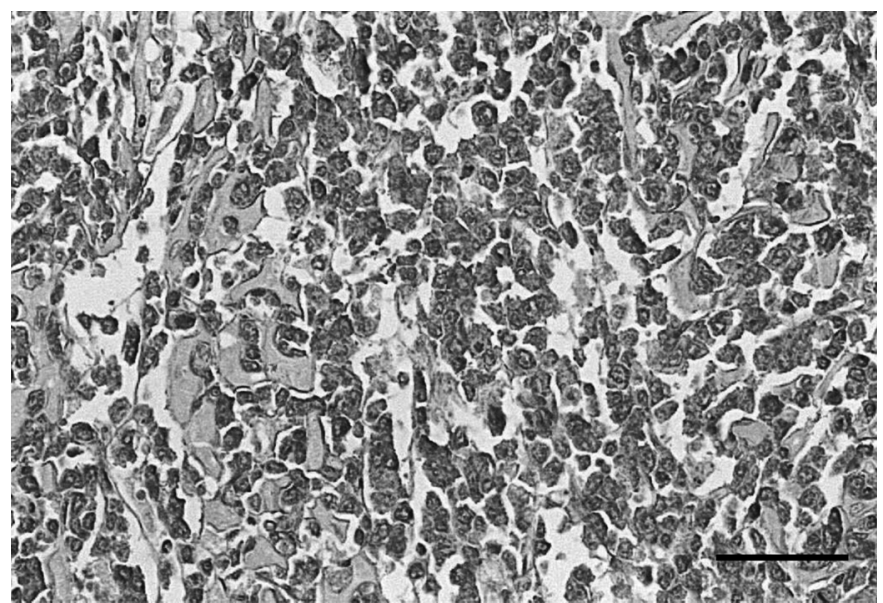

Fig.10. Canino das Figuras 7 e 8. Células neoplásicas fortemente positivas para linfócitos B (anticorpo anti-BLA36). IHQ pelo método estreptavidina-biotina-peroxidase, barra $50 \mu \mathrm{m}$.

e alterações de insuficiência cardíaca direita, caracterizadas por fígado congesto com evidenciação do padrão lobular. Um segundo Rottweiler, de 2 anos, também com linfoma e inúmeros focos de metástase ventricular, apresentou fígado de tamanho diminuído e consistência aumentada, e inúmeros nódulos amarelados distribuídos na superfície do órgão, que microscopicamente correspondiam a nódulos de regeneração. Neste canino, os vasos sanguíneos mesentéricos e a veia cava caudal formavam várias anastomoses portossistêmicas.

Os vários marcadores imuno-histoquímicos descritos neste trabalho foram aplicados às neoplasias diagnosticadas como tumores de células redondas, como o linfoma (Fig.8) e a histiocitose maligna sistêmica. Entre os linfomas, seis foram positivos na imuno-histoquímica para o marcador de linfócito T (CD3) (Fig.9), e um positivo para o marcador de linfócitos B (BLA36), o qual marca tanto linfócitos B jovens, como ativados (Jacobs et al. 2002) (Fig.10). Nenhum caso foi positivo para o marcador de linfócito B (Lambda light chain) e para o marcador de mastócitos (CD117). 0 caso 
diagnosticado como histiocitose maligna sistêmica (Fig.11) foi baseado nos aspectos histopatológicos e na forte marcação imuno-histoquímica para CD18 (Fig.12) e ausência de marcação para CD3, CD117, Lambda light chain e BLA.36, semelhantemente ao descrito por Affolter \& Moore (2002). Os hemangiossarcomas metastáticos apresentaram forte marcação imuno-histoquímica para o fator VIII.

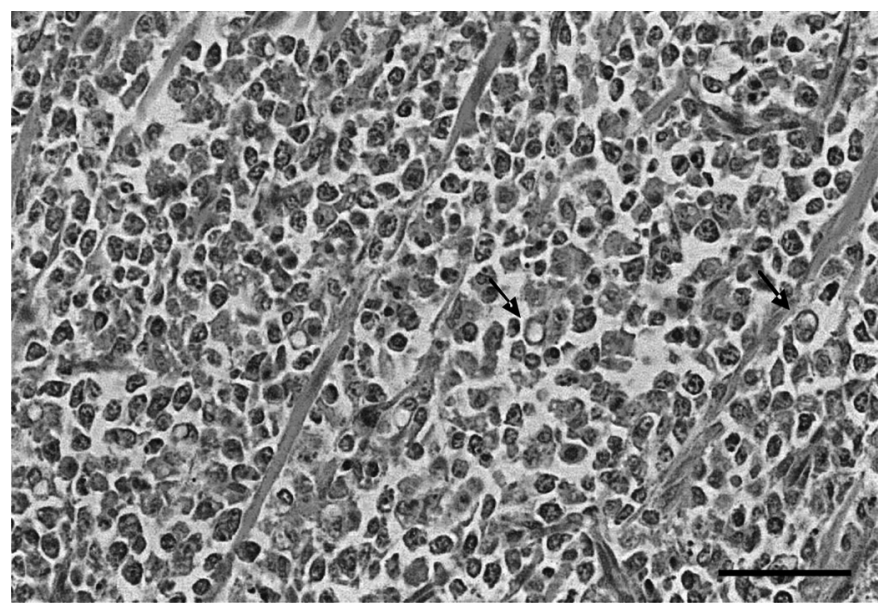

Fig.11. Histiocitose maligna sistêmica em canino, fêmea, Boxer, com 7 anos de idade. Neoplasia cardíaca composta por células grandes, arredondadas a poligonais, com núcleos predominantemente ovalados e citoplasma abundante, situadas entre fibras cardíacas. Nota-se fagocitose de debris celulares pelas células neoplásicas (setas). HE, barra $50 \mu \mathrm{m}$.

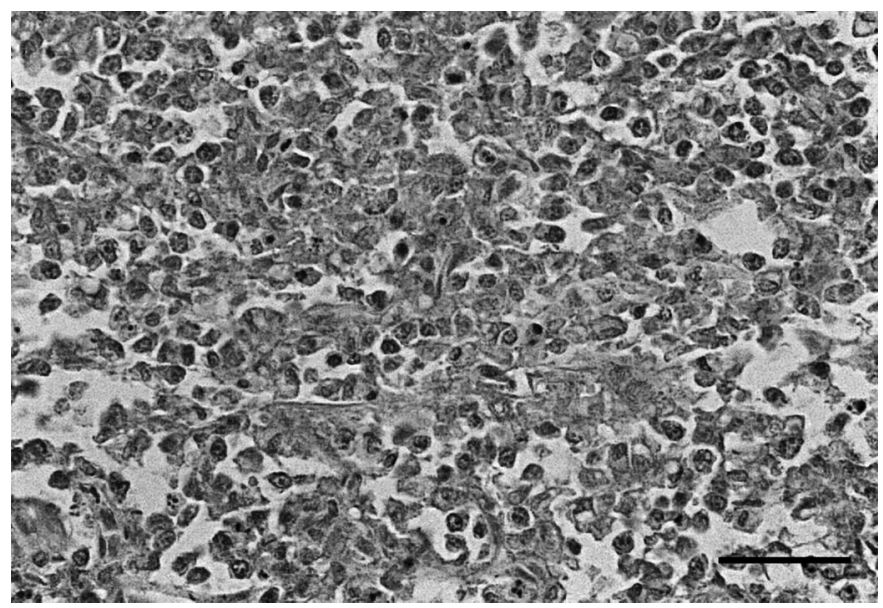

Fig.12. Histiocitose maligna sistêmica, coração, canino, fêmea, Boxer, com 7 anos de idade. Marcação intracitoplasmática positiva para histiócitos (anticorpo anti-CD18). IHQ pelo método estreptavidina-biotina-peroxidase, barra $50 \mu \mathrm{m}$.

\section{DISCUSSÃO}

No presente estudo, as neoplasias cardíacas, tanto primárias como secundárias, tiveram prevalência de 1,29\%. Em estudos similares, as prevalências variaram de 0,19\% (Ware \& Hopper 1999) a 3,06\% (Walter \& Rudolph 1996, Girard et al. 1999). As neoplasias metastáticas $(79,42 \%)$ foram mais frequentes que as primárias (20,58\%). Estes achados estão de acordo com os descritos por Walter \& Rudolph (1996), os quais encontraram 73,78\% de neoplasias metastáticas para o coração e somente $26,22 \%$ de neopla- sias primárias do coração e são comparáveis aos de Aupperle et al. (2007) que, de 83 cães com doença neoplásica terminal, $24(68,57 \%)$ possuíam neoplasias metastáticas no coração, enquanto que $11(31,43 \%)$ apresentaram neoplasias primárias do coração. No entanto, Ware \& Hopper (1999) descrevem uma maior frequência de neoplasias cardíacas primárias (84\%) em relação aos tumores metastáticos (16\%).

Neste estudo, as neoplasias primárias da base do coração foram mais frequentes que as do coração, com maior ocorrência para o quimiodectoma. Dos tumores primários do coração, foram diagnosticados somente um caso de hemangiossarcoma e um de mixoma. 0 hemangiossarcoma é descrito como o mais frequente, seguido pelo quimiodectoma (Walter \& Rudolph 1996, Girard et al. 1999, Ware \& Hopper 1999, Aupperle et al. 2007). O hemangiossarcoma primário ocorreu em um Pastor Alemão, descrita como a raça mais afetada por esse tipo de tumor (Aronsohn 1985, Walter \& Rudolph 1996). No presente estudo, o hemangiossarcoma localizado no átrio direito foi considerado primário, uma vez que em vários estudos todos os hemangiossarcomas considerados primários do coração encontravam-se nesta localização (Aronsohn 1985, Aupperle et al. 2007), além disso, o tamanho da neoplasia atrial $(1,5 \mathrm{~cm})$ em relação aos outros focos $(0,3-0,6 \mathrm{~cm})$ era consideravelmente maior. Porém a possibilidade de origem multicêntrica em alguns casos não pode ser totalmente descartada. Já os quimiodectomas ocorrem mais comumente em raças braquicefálicas, o que pode estar relacionado à hipóxia crônica (Patnaik et al. 1975, Walter \& Rudolph 1996, Kisseberth 2001). Dentro deste grupo racial, o Boxer e o Boston Terrier são os mais acometidos (Patnaik et al. 1975). No presente estudo todos os cães com quimiodectoma eram da raça Boxer, e o diagnóstico nestes casos foi baseado nos aspectos histopatológicos e principalmente pela marcação imuno-histoquímica positiva para cromogranina A e negativa para tireoglobulina. Os dois casos de carcinoma de tireoide ectópica puderam ser confirmados por meio da imuno-histoquímica, os quais foram positivos para tireoglobulina e negativos para cromogranina A. A tireoglobulina e a cromogranina $A$, no presente estudo, foram importantes para a diferenciação entre o carcinoma de tireóide ectópico e o quimiodectoma, semelhantemente ao descrito por Paltrinieri et al. (2004). As neoplasias dos caninos 3 e 5 também foram positivas para enolase neurônio específica e sinaptofisina. Estes dois anticorpos também são úteis para o diagnóstico dos quimiodectomas (Walter \& Rudolph 1996, Nakagawa et al. 2009).

A neoplasia metastática mais frequente foi o linfoma, com 29,16\% (7/24); dados semelhantes são descritos por Girard et al. (1999). Em alguns tumores classificados anteriormente dentro do grupo de células redondas, somente com a marcação imuno-histoquímica foi possível o diagnóstico definitivo. Esta também evidenciou uma maior frequência de linfomas de células $\mathrm{T}$, onde seis neoplasias foram positivas para o marcador CD3, e uma originada de linfócitos B, positiva para BLA36. 0 anticorpo BLA36 identifica linfócitos B imaturos e ativados (Della Croce et al. 1991, Jacobs et al. 2002). A importância desta caracteriza- 
ção ante mortem está relacionada ao prognóstico, uma vez que em cães, linfomas de células $\mathrm{T}$ apresentam uma resposta menor à quimioterapia, assim como, recidivam mais rapidamente e, consequentemente o tempo de sobrevida destes cães é menor quando comparado aos linfomas tipo $\mathrm{B}$ (Jacobs et al. 2002). Este tumor foi negativo para a cadeia leve Lambda, também utilizada como marcador de linfócitos B (Jacobs et al. 2002), o que provavelmente poderia ser explicado pelo estado de maturação dos linfócitos B.

Os sinais clínicos, quando presentes, nos cães deste estudo foram variáveis. 0 canino com mixoma possuía neoplasia relativamente grande, embora não apresentasse alterações clínicas e eletrocardiográficas referentes à mesma. Por outro lado, hemangiossarcoma primário do coração geralmente está associado a efusão pericárdica hemorrágica e metástases (Kisseberth 2001). Esses achados foram observados no canino 2 com hemangiossarcoma. 0 quimiodectoma do canino 4 era localmente invasivo, o que é descrito por Kisseberth (2001), e o referido animal apresentou sinais clínicos de disfunção cardiovascular. No canino 5, não havia descrição da sintomatologia clínica, porém, outras lesões encontradas como hipertrofia concêntrica moderada do ventrículo esquerdo, dilatação do ventrículo direito, endocardiose moderada das valvas tricúspide e mitral e endocardite valvular moderada na mitral e semilunar aórtica, provavelmente contribuíram para a doença clínica.

Outros cães, onde estas avaliações foram realizadas, não apresentaram sinais clínicos ou alterações em exames complementares, provavelmente devido ao tamanho reduzido do tumor (caninos 2 e 3). A evolução do quadro clínico para a morte foi relativamente rápida em alguns cães com neoplasia primária (caninos 4 e 6), com variação de 15 a 30 dias. Morte súbita, ou num curto período de tempo, são associadas à arritmia cardíaca (Kisseberth 2001).

Entre os caninos com tumores metastáticos para o coração, um canino com metástase de linfoma apresentou bradicardia e arritmias e outro cão, com o mesmo tipo de neoplasia, apresentou sopro cardíaco, sinal clínico provavelmente não relacionado ao tumor.

As metástases cardíacas dos diversos tumores estudados foram observadas principalmente nos ventrículos. Com base nisso, são sugeridas seções detalhadas do coração de pacientes com neoplasias, para a identificação de metástases pequenas, especialmente na parede livre do ventrículo esquerdo e no ápice do septo interventricular (Aupperle et al. 2007).

Os resultados aqui apresentados demonstram que a imuno-histoquímica é uma ferramenta essencial para o diagnóstico das várias neoplasias que afetam o coração, principalmente nos tumores de células redondas e daqueles originados da base do coração.

Agradecimentos.- À Coordenação de Aperfeiçoamento de Pessoal de Nível Superior (CAPES), pela concessão da bolsa de mestrado e à Fapemig pelo apoio financeiro. Aos doutores David Driemeier, Felipe Augusto Ruiz Sueiro e Rogéria Serakides pela colaboração em algumas análises de imuno-histoquímica em neoplasias primárias do coração.

\section{REFERÊNCIAS}

Affolter V.K. \& Moore P.F. 2002. Localized and disseminated histiocytic sarcoma of dendritic cell origin in dogs. Vet. Pathol. 39:74-83.
Akkoc A., Ozyigit M.O. \& Cangul I.T. 2007. Valvular cardiac myxoma in a dog. J. Vet. Med. A. 54:356-358.

Albers T.M., Alroy J., Garrod L.A., Brown D. \& Penninck D. 1997. Histochemical and ultrastructural characterization of primary cardiac chondrossarcoma. Vet. Pathol. 34:150-151.

Almes K.M., Heaney A.M. \& Andrews G.A. 2008. Intracardiac ectopic thyroid carcinosarcoma in a dog. Vet. Pathol. 45:500-504.

Aronsohn M. 1985. Cardiac hemangiosarcoma in the dog: A review of 38 cases. J. Am.Vet. Med. Assoc. 187(9):922-926.

Aupperle H., Marz I., Ellenberger C., Buschatz S., Reischauer A. \& Schoon H.-A. 2007. Primary and secondary heart tumors in dogs and cats. J. Comp. Pathol. 136:18-26.

Ben-Amotz R., Ellison G.W., Thompson M.S., Sheppard B.J., Estrada A.H. \& Levy J.K. 2007. Pericardial lipoma in a geriatric dog with an incidentally discovery thoracic mass. J. Small Anim. Pract. 48:596-599.

Brambilla P.G., Roccabianca P., Locatelli C., Di Giancamillo M., Di Marcello M. \& Pittoru M. 2006. Primary cardiac lipoma in a dog. J. Vet. Intern. Med. 20:691-693.

Brower A., Herold L.V. \& Kirby B.M. 2006. Canine cardiac mesothelioma with granular cell morphology. Vet. Pathol. 46:384-387.

Cavalcanti G.A.O., Muzzi R.A.L., Bezerra Júnior P.S., Nogueira R.B. \& Varaschin M.S. 2006. Fibrilação atrial em cão associado ao quimiodectoma infiltrativo atrial; relato de caso. Arq. Bras. Med. Vet. Zootec. 58(6):10431047.

Cobb M.A. \& Brownlie S.E. 1992. Intrapericardial neoplasia in 14 dogs. J. Small Anim. Pract. 33:309-316.

Constantino-Casas F., Rodríguez-Martínez H.A. \& Gutiérrez Díaz-Ceallos MA.E. 1996. A case report and review: The gross, histological and immunohistochemical characteristics of a carcinoma of ectopic thyroid in a dog. Brit. Vet. J. 152:669-672.

Della Croce D.R., Iman A., Brynes R.K., Nathwani B.N. \& Taylor C.R. 1991. Anti-BLA.36 monoclonal antibody shows reactivity with hodgkin's cells and B lymphocytes in frozen and paraffin-embedded tissues. Hematol. Oncol. 9(2):103-114.

Fews D., Scase T.J. \& Battersby I.A. 2008. Leiomyosarcoma of the pericardium, with epicardial metastases and peripheral eosinophilia in a dog. J. Comp. Pathol. 138:224-228.

Girard C., Hélie P. \& Odin M. 1999. Intrapericardial neoplasia in dogs. J. Vet. Diagn. Invest. 11:73-78.

Grieco V., Locatelli C., Riccardi E. \& Brambilla P. 2008. A case of two different tumors in a heart of a dog. J. Vet. Diagn. Invest. 20:365-368.

Headley S.A., Bracarense A.P., Nakagawa T., Moreno K., Pereira P.M. \& Reis A.C.F. 2009. Aortic body tumors in dogs from Northern Paraná, Brazil. Ciênc. Rural 39(6):1908-1912.

Jacobs R.M., Messick J.B. \& Valli V.E. 2002. Tumors of hemolymphatic system, p.119-198. In: Meuten D.J. (Ed.), Tumors in Domestic Animals. Iowa State Press, Iowa. 769p.

Kim S.-K., Hyun C.-B. \& Cho K.-O. 2005. Unusual metastasis of malignant aortic body tumor to multiple bones in a dog. J. Vet. Med. Sci. 67(6):625627.

Kisseberth W.C. 2001. Neoplasia of the heart, p.661-667. In: Withrow S.J. \& MacEwen E.G. (Eds), Small Animal Clinical Oncology. W.B. Saunders Company, Philadelphia. 718p.

LaRock R.G., Ginn P.E., Burrows C.F., Newell S.M. \& Henson K.L. 1997. Primary mesenchymal chondrosarcoma in the pericardium of a dog. J. Vet. Diagn. Invest. 9:410-413.

Machida N., Hoshi K., Kobayashi M., Katsuda S. \& Yamane Y. 2003. Cardiac myxoma of the tricuspid valve in a dog. J. Comp. Pathol. 129:320-324a.

Machida N., Kobayashi M., Tanaka R., Katsuda S. \& Mitsumori K. 2002. Primary malignant mixed mesenchymal tumour of the heart in a dog. J. Comp. Pathol. 128:71-74.

Madarame H., Sato K., Ogihara K., Ishibashi T., Fugii Y. \& Wakao Y. 2004. Primary cardiac fibrossarcoma in a dog. J. Vet. Med. Sci. 66(8):979-982.

Nakagawa T.L.D.R., Sakai H., Yanai T., Kitoh K., Mori T., Murakami M. \& Masegi T. 2009. Simultaneous aortic body tumor and pulmonary histiocytic sarcoma in a Flat-Coated Retriever. J. Vet. Med. Sci. 71(9):1221-1223. 
Paltrinieri S., Riccaboni P., Rondena M., Giudice C. 2004. Pathologic and immunohistochemical findings in a feline aortic body tumor. Vet. Pathol. 41:195-198.

Patnaik A.K., Liu S.-K., Hurvitz A.I. \& McClelland A.J. 1975. Canine chemodectoma (extra-adrenal paragangliomas): A comparative study. J. Small Anim. Pract. 16:785-801

Radi Z.A. \& Metz A. 2009. Canine cardiac rhabdomyoma. Toxicol. Pathol. 37:348-350.

Schelling S.H. \& Moses B.L. 1994. Primary intracardiac osteossarcoma in a dog. J. Vet. Diagn. Invest. 6:396-398.

Speltz M.C., Manivel J.C., Tobias A.H. \& Hayden D.W. 2007. Primary cardiac fibrossarcoma with pulmonary metastasis in a Labrador Retriever. Vet. Pathol. 44:403-407.
Symbas P.N., Hatcher C.R. \& Gravanis M.B. 1976. Myxoma of the heart: clinical and experimental observations. Ann. Surg. 183(5):470-474.

Walter J.H. \& Rudolph R. 1996. Systemic, metastatic, eu- and heterotope tumours of the heart in necropsied dogs. J. Vet. Med. A 43:31-45.

Ware W.A. \& Hopper D.L. 1999. Cardiac tumors in dogs: 1982 -1995. J. Vet. Intern. Med. 13:95-103.

Warman S.M., Mcgregor R., Fews D. \& Ferasin L. 2006. Congestive heart failure caused by intracardiac tumours in two dogs. J. Small Anim. Pract. 47:480-483.

Wohlsein P., Cichowski S. \& Baumgärtner W. 2005. Primary endocardial malignant spindle-cell sarcoma in the right atrium of a dog resembling a malignant peripheral nerve sheath tumour. J. Comp. Pathol. 132:340345 . 